\title{
Demonstrate the removal efficiency and capacity of MOF materials for krypton recovery
}

Fuel Cycle Research \& Development

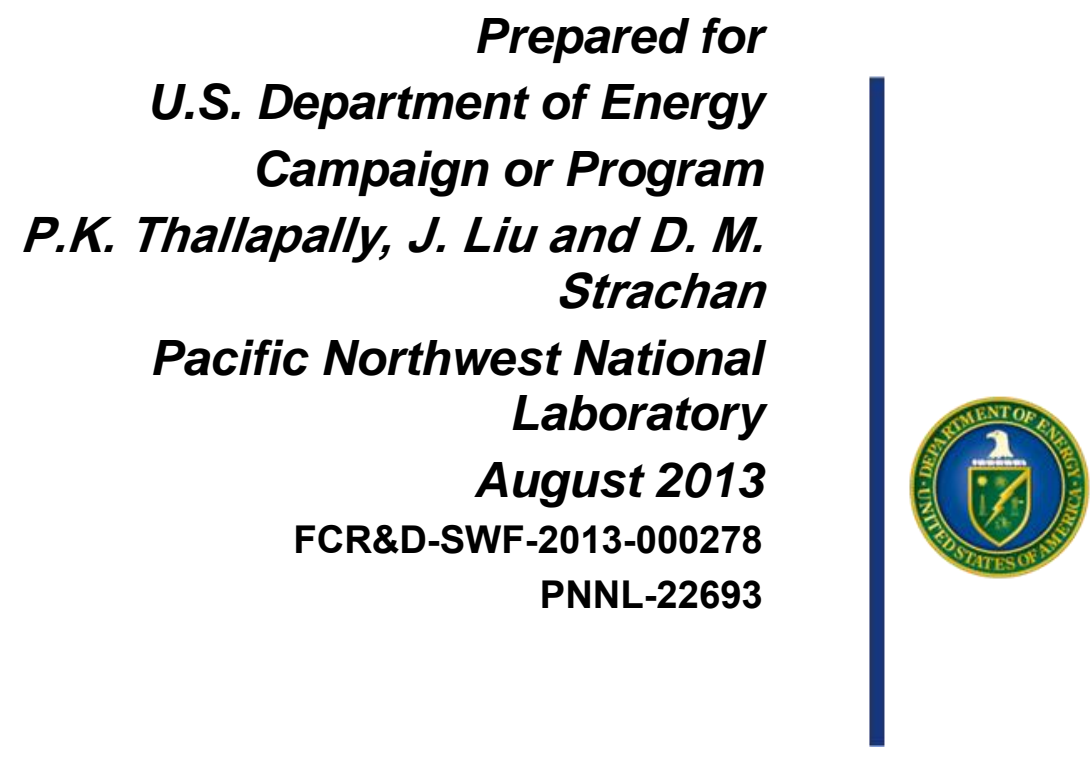




\section{DISCLAIMER}

This information was prepared as an account of work sponsored by an agency of the U.S. Government. Neither the U.S. Government nor any agency thereof, nor any of their employees, makes any warranty,

expressed or implied, or assumes any legal liability or responsibility for the accuracy, completeness, or usefulness, of any information, apparatus, product, or process disclosed, or represents that its use would not infringe privately owned rights. References herein to any specific commercial product, process, or service by trade name, trade mark, manufacturer, or otherwise, does not necessarily constitute or imply its endorsement, recommendation, or favoring by the U.S. Government or any agency thereof. The views and opinions of authors expressed herein do not necessarily state or reflect those of the U.S. Government or any agency thereof. 


\section{SUMMARY}

Metal organic framework materials (MOFs) were developed and tested in support of the U.S. Department of Energy Office of Nuclear Energy, Fuel Cycle Technology Separations and Waste Forms Campaign. Specifically, materials are being developed for the removal of xenon (Xe) and krypton (Kr) from gaseous products of nuclear fuel reprocessing unit operations.

Two metal organic framework structures were investigated in greater detail to demonstrate the removal efficiency and capacity of MOF materials for krypton recovery. Our two bed breakthrough measurements on NiDOBDC and FMOFCu indicate these materials can capture and separate parts per million levels of $\mathrm{Xe}$ and $\mathrm{Kr}$ from air. The removal efficiency and adsorption capacity for $\mathrm{Kr}$ on these two MOFs were further increased upon removal of Xe upfront. 
DEMONSTRATE THE REMOVAL EFFICIENCY AND CAPACITY OF MOF MATERIALS FOR KRYPTON RECOVERY

August 2013 


\section{CONTENTS}

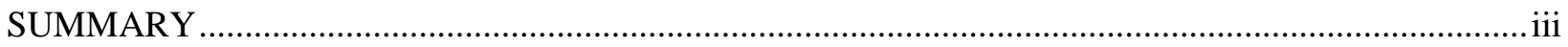

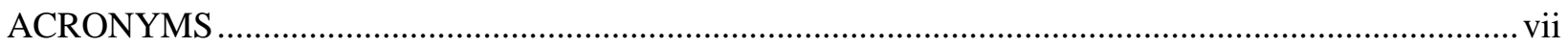

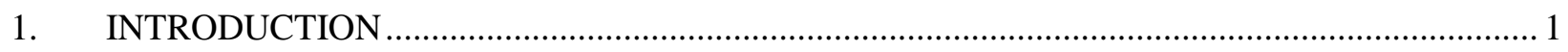

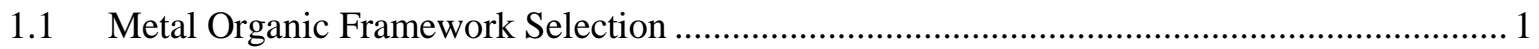

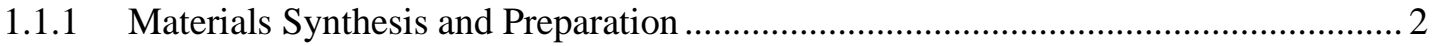

1.1.2 Two Bed Approach for Removal of Xe and Kr with MOFs .................................... 3

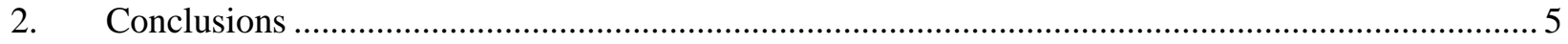

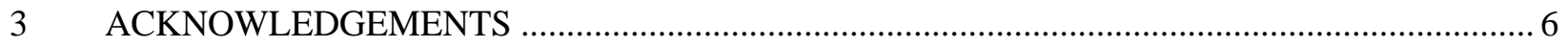

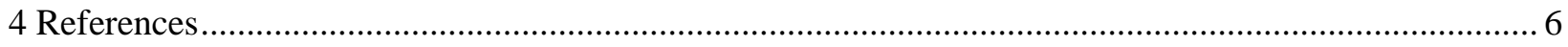

\section{FIGURES}

Figure 1. Crystal structures for MOFs after removing solvent molecules........................................... 2

Figure 2. Modified two bed breakthrough reactor coupled with mass spectroscopy ................................. 2

Figure 3. Breakthrough curves for gas mixtures using two bed adsorption modules at 233K. Adsorbents in bed 1 and 2 are NiDOBDC. a) Gas mixture [Xe (400 ppm), $\mathrm{Kr}(40 \mathrm{ppm})$ in air] into bed-1, b) gas breakthrough from bed 1, c) Gas mixture from bed 1 (Xe removed) introduced to bed $2 \mathrm{~d}$ ) breakthrough of $\mathrm{Kr}$ from bed-1.

Figure 4. Breakthrough curves for gas mixture using two bed adsorption modules coupled with mass spectrometry at 233K. Adsorbents in bed 1 and 2 are NiDOBDC and FMOF-Cu. a) Gas mixture [Xe (400 ppm), Kr (40 ppm) in air] into bed-1, b) gas breakthrough from bed 1, c) Gas mixture from bed 1 (Xe removed) introduced to bed $2 \mathrm{~d}$ ) breakthrough of $\mathrm{Kr}$ from bed-1.

Figure 5. Desorption of $\mathrm{Kr}$ from bed 2 loaded with the NiDOBDC and FMOFCu by purging with $\mathrm{He}$.

\section{TABLES}

Table 1. Krypton capacities of the MOFs at 233K from gas mixture containing with and without Xe from air. 
DEMONSTRATE THE REMOVAL EFFICIENCY AND CAPACITY OF MOF MATERIALS FOR KRYPTON RECOVERY

August 2013

vi 


\section{ACRONYMS}

\begin{tabular}{|l|l|}
\hline CPHFP & 2,20-bis(4-carboxyphenyl) hexafluoropropane \\
\hline DMF & N,N-dimethylformamide \\
\hline FMOFCu & Fluorinated metal organic framework \\
\hline MOF & Metal Organic Framework \\
\hline NiDOBDC & Nickel Dioxobenzenedicarboxylic acid \\
\hline PNNL & Pacific Northwest National Laboratory \\
\hline ppm & Parts per million \\
\hline sccm & Standard cubic centimetres per minute \\
\hline THF & Tetrahydrofuran \\
\hline
\end{tabular}


August 2013

viii 


\section{DEMONSTRATE THE REMOVAL EFFICIENCY AND CAPACITY OF MOF MATERIALS FOR KRYPTON RECOVERY}

\section{INTRODUCTION}

During reprocessing, fission-product noble gases are released when the fuel cladding is breached and any fuel processing is performed. Two of these gases are xenon (Xe) and krypton $(\mathrm{Kr})$. Although $\mathrm{Xe}$ is generated as fission product, by the time the fuel is reprocessed, all the radioactive isotopes have decayed to very low concentrations. Never-the-less, non-radioactive $\mathrm{Xe}$ is at a higher concentration than $\mathrm{Kr}$. Krypton has two long-lived isotopes ${ }^{81} \mathrm{Kr}\left[\mathrm{t}_{1 / 2}=2.1 \times 10^{5} \mathrm{y}\right]$ and ${ }^{85} \mathrm{Kr}\left[\mathrm{t}_{1 / 2}=10.7 \mathrm{y}\right]$. Of these, ${ }^{85} \mathrm{Kr}$ is the isotope of regulatory concern and cannot be freely released if fuel younger than roughly $30 \mathrm{y}$ is processed. In an operating reprocessing plant, ${ }^{85} \mathrm{Kr}$ is diluted with process air making its removal difficult because of the low concentrations.

The demonstrated processes to remove $\mathrm{Xe}$ and $\mathrm{Kr}$ from nuclear fuel processing off-gas are cryogenic distillation and cryogenic absorption. By cryogenic distillation, the air is cooled and liquefied/partially solidified. At liquid air temperatures, $\mathrm{Xe}$ and $\mathrm{Kr}$ are solids and can be separated from air by cryogenic distillation, leaving behind a mixture of $\mathrm{Xe}$ and $\mathrm{Kr}$ and possibly argon (Ar) (Daney 1991). By cryogenic absorption, process air is cooled to near liquid temperatures where the absorption capacity of zeolites can effectively separate $\mathrm{Xe}$ and $\mathrm{Kr}$ from the air and from each other. Installing and operating a cryogenic process is very expensive and energy intensive. Thus, a process in which these gases are removed at much higher temperatures would be advantageous, especially if the process could operate at close to ambient conditions and the materials used in the process are cost competitive. Zeolites and activated carbon have been tested for $\mathrm{Xe}$ and $\mathrm{Kr}$ separation with high selectivities (Xe/Kr of 3 to 4) but with very low capacities (20 to 30 mass\% at 1 bar and RT) (Jameson et al. 1997; Bazan et al. 2011; Munakata et al. 2003). In this regard, metal organic framework (MOF) materials have been shown to have improved capacities ( 60 mass \% at 1 bar and RT) and selectivities at room temperature compared to any known porous material tested thus far. Among all the MOF materials tested at PNNL, nickel dioxobenzenedicarboxylic acid (NiDOBDC) and a partially fluorinated MOF with copper (FMOFCu) have shown improved $\mathrm{Xe}$ and $\mathrm{Kr}$ capacities at room temperature relative to previous materials. With these MOFs, $\mathrm{Xe}$ and $\mathrm{Kr}$ at parts per million concentrations have been removed from air at room temperature with NiDOBDC and FMOFCu and the selectivity of FMOFCu was found to change from Xe $>\mathrm{Kr}(6.0$ mass \% at $\mathrm{RT})$ to $\mathrm{Xe}<\mathrm{Kr}\left(14.7\right.$ mass $\%$ at $\left.-40{ }^{\circ} \mathrm{C}\right)$ simply by changing the temperature (Strachan et al. 2010; Strachan et al. 2011; Thallapally and Strachan 2012).

In this report, we demonstrate the removal of $\mathrm{Xe}$ and $\mathrm{Kr}$ and determine the capacities using a two bed approach at room and near-room temperatures.

\subsection{Metal Organic Framework Selection}

Two benchmark MOFs - Ni/DOBDC and FMOFCu, shown schematically in Figure 1 (left, and right, respectively) - were studied for $\mathrm{Xe}$ and $\mathrm{Kr}$ adsorption with a dynamic two bed breakthrough column method. These MOFs were selected for three reasons. First, both MOFs contain unsaturated metal centers that are polar and favorable for $\mathrm{Xe}$ and $\mathrm{Kr}$ adsorption. Second, the NiDOBDC is known to have high hydrothermal stability (Eddaoudi et al. 2002; Liu 2012; Sanchez et al. 2011; Thallapally et al. 2012) 
and higher Xe capacity than activated carbon (45 mass\% over 55 mass\%). Third, Ni/DOBDC has a uniform, 11-nm cylindrical pore and shown to remove Xe at ppm concentrations.

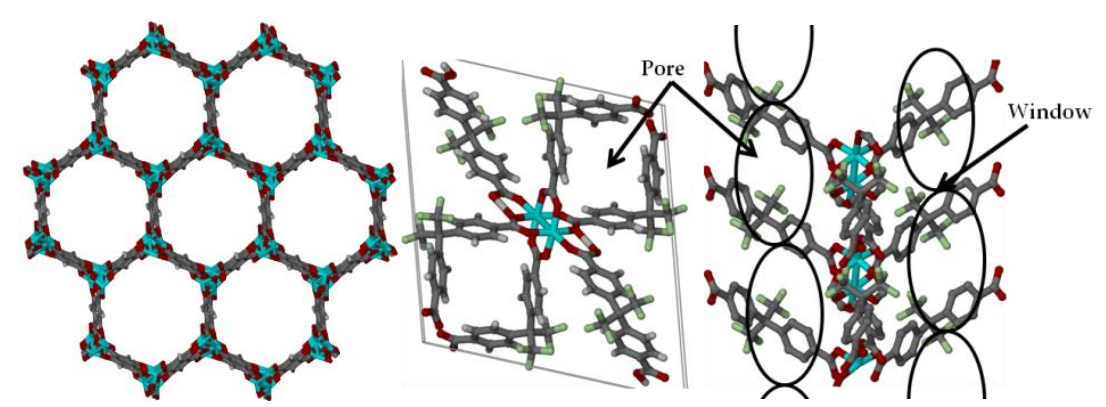

Figure 1. Crystal structures for MOFs after removing solvent molecules. Left: Ni/DOBDC; and right: FMOFCu.

An important feature of FMOFCu (Figure 1) is that the $0.5 \times 0.5-\mathrm{nm}$ tubular cavities are connected through small (bottleneck) windows $(0.35 \times 0.35 \mathrm{~nm})$. Although FMOFCu cages are larger than the kinetic diameters of $\mathrm{Xe}$ and $\mathrm{Kr}(0.396 \mathrm{~nm}$ and $0.360 \mathrm{~nm}$, respectively), they were selected because the connecting windows have dimensions practically similar to the kinetic diameter of $\mathrm{Kr}$ and are smaller than the corresponding kinetic diameter of Xe. Therefore, Xe diffusion into the cavities should be restricted, giving FMOFCu higher $\mathrm{Kr}$ selectivity than NiDOBDC, based on molecular sieving, where the connecting windows are much larger than the kinetic diameters of $\mathrm{Xe}$ or $\mathrm{Kr}$.

\subsubsection{Materials Synthesis and Preparation}

The NiDOBDC was synthesized following a procedure reported in the literature (Bonino et al. 2008). Briefly, a solution of 2,5 dihydroxyterephthalic acid (1.486 g, $7.5 \mathrm{mmol})$ in tetrahydrofuran (THF) (25 $\mathrm{mL})$ and a solution of nickel (II) acetate tetrahydrate $(3.733 \mathrm{~g}, 15 \mathrm{mmol})$ in water $(25 \mathrm{~mL})$ were combined in a Teflon ${ }^{\circledR}$-lined, $100 \mathrm{~mL}$ stainless-steel pressure vessel. The reaction was conducted for 3 days at $110{ }^{\circ} \mathrm{C}$. Filtration yielded $3.169 \mathrm{~g}$ of a yellowish, fine crystalline product that was washed three times with water $(50-100 \mathrm{~mL})$ and dried in air at $85^{\circ} \mathrm{C}$ under vacuum.

The synthesis of FMOFCu was performed following a similar procedure. Copper nitrate trihydrate $\left(\mathrm{Cu}\left(\mathrm{NO}_{3}\right)_{2} \times 3 \mathrm{H}_{2} \mathrm{O}(99 \%\right.$ from Aldrich Chemicals) and 2,20-

bis(4-carboxyphenyl)hexafluoropropane (CPHFP) (99\%; Aldrich Chemicals) were used as received without further purification. Crystals of FMOFCu were obtained by a hydrothermal reaction of $\mathrm{Cu}\left(\mathrm{NO}_{3}\right)_{2} \cdot 3 \mathrm{H}_{2} \mathrm{O}(0.024 \mathrm{~g}, 0.1 \mathrm{mmol})$ with an excess of CPHFP $(0.122 \mathrm{~g}$, $0.31 \mathrm{mmol}$ ) in $5 \mathrm{~mL}$ of deionized water at $150{ }^{\circ} \mathrm{C}$ for $12 \mathrm{~h}$. The molar ratio of the reaction was $1: 3: 2778\left(\mathrm{Cu}\left(\mathrm{NO}_{3}\right)_{2}\right.$ :

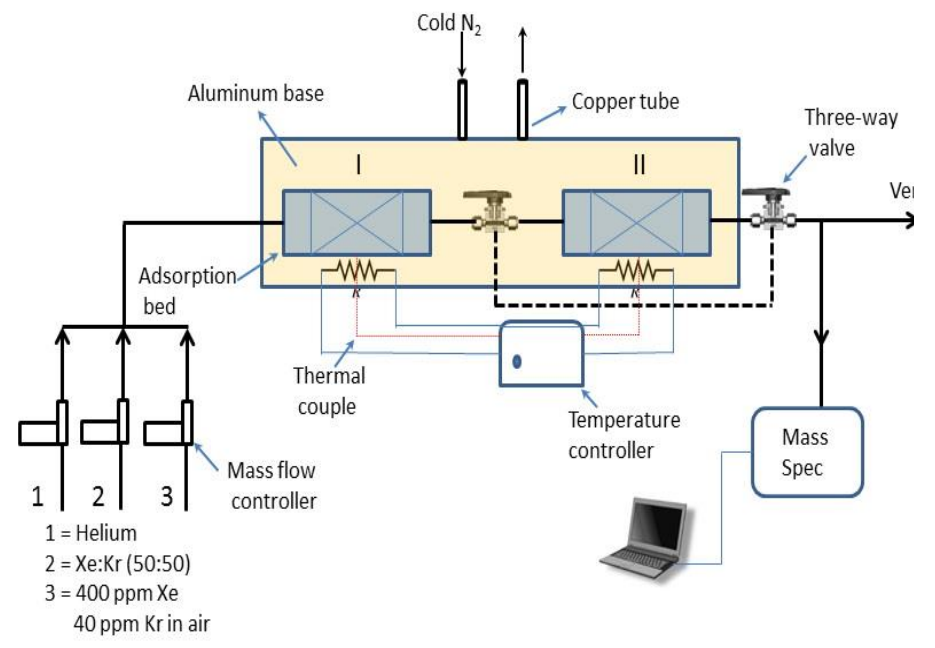

Figure 2. Modified two bed breakthrough reactor coupled with mass spectroscopy. 
CPHFP : Solvent). Excess CPHFP was removed with repeated washing of the product with $10 \mathrm{~mL}$ aliquots of $\mathrm{N}, \mathrm{N}$-dimethylformamide (DMF), followed by drying the product in air for an hour.

To minimize the pressure drop and prevent potential contamination to the instrument, coarse MOF granules were formed from a powder sample with no binder that was pressed into a disk under $12 \mathrm{MPa}$ for 5 minutes. The disk was carefully broken into fragments and sieved to 20-30 mesh $(600-850 \mu \mathrm{m})$. This process was repeated to make sufficient granules for the experiment. Pure helium ( $\mathrm{He}), \mathrm{Xe}$, and $\mathrm{Kr}$ gases (OXARC, Inc., Spokane, WA) were used without further purification. The low concentration Xe and $\mathrm{Kr}$ mixtures (OXARC Inc.) came with certified Xe and $\mathrm{Kr}$ concentrations of 400 and 40 ppm, respectively, in dry air.

\subsubsection{Two Bed Approach for Removal of Xe and Kr with MOFs}

To demonstrate the removal efficiency and capacity of MOF materials, we used multiple adsorption beds containing either the same or a combination of NiDOBDC or FMOFCu to remove Xe upfront on bed 1 at $233 \mathrm{~K}$. The resulting gas mixture was sent to bed 2 also at $233 \mathrm{~K}\left(-40{ }^{\circ} \mathrm{C}\right)$ where $\mathrm{Kr}$ was selectively removed. Our hypothesis was that by removing Xe in bed 1, the adsorption capacity of $\mathrm{Kr}$ would be higher in bed 2 because Xe was no longer present to compete for sorption sites. These experiments were performed at $233 \mathrm{~K}$ because the breakthrough for $\mathrm{Xe}$ and $\mathrm{Kr}$ would be too short for the experimental set-up we used. Therefore, selection of $233 \mathrm{~K}$ as the test temperature allowed sufficient time for use to switch between one adsorption bed to another. This shortcoming was an artifact of the analytical equipment; in actual operation a single, two-stage system may be used at higher temperatures.

Prior to breakthrough experiments, samples were activated at high temperature $\left(200{ }^{\circ} \mathrm{C}\right)$ with a He purge. Two separate experiments were conducted with the two stage adsorption modules as shown in Figure 2. In the first experiment, both beds were loaded with $0.92 \mathrm{~g}$ of NiDOBDC. In the second experiment, bed 1 was loaded with $0.92 \mathrm{~g}$ of NiDOBDC and bed 2 was loaded with $1.15 \mathrm{~g}$ FMOFCu. The Xe and $\mathrm{Kr}$ mixture in air (400 ppm Xe and 40 ppm Kr in a dry air) with a flow rate of $330 \mathrm{~mm}^{3} / \mathrm{s}(20 \mathrm{sccm})$ was passed through the bed 1 till the outlet concentration of $\mathrm{Kr}$ reach a constant that was equal to inlet concentration. At this point, the outlet gas mixture (40 ppm Kr in dry air with less-than-detectable Xe) from bed 1 was

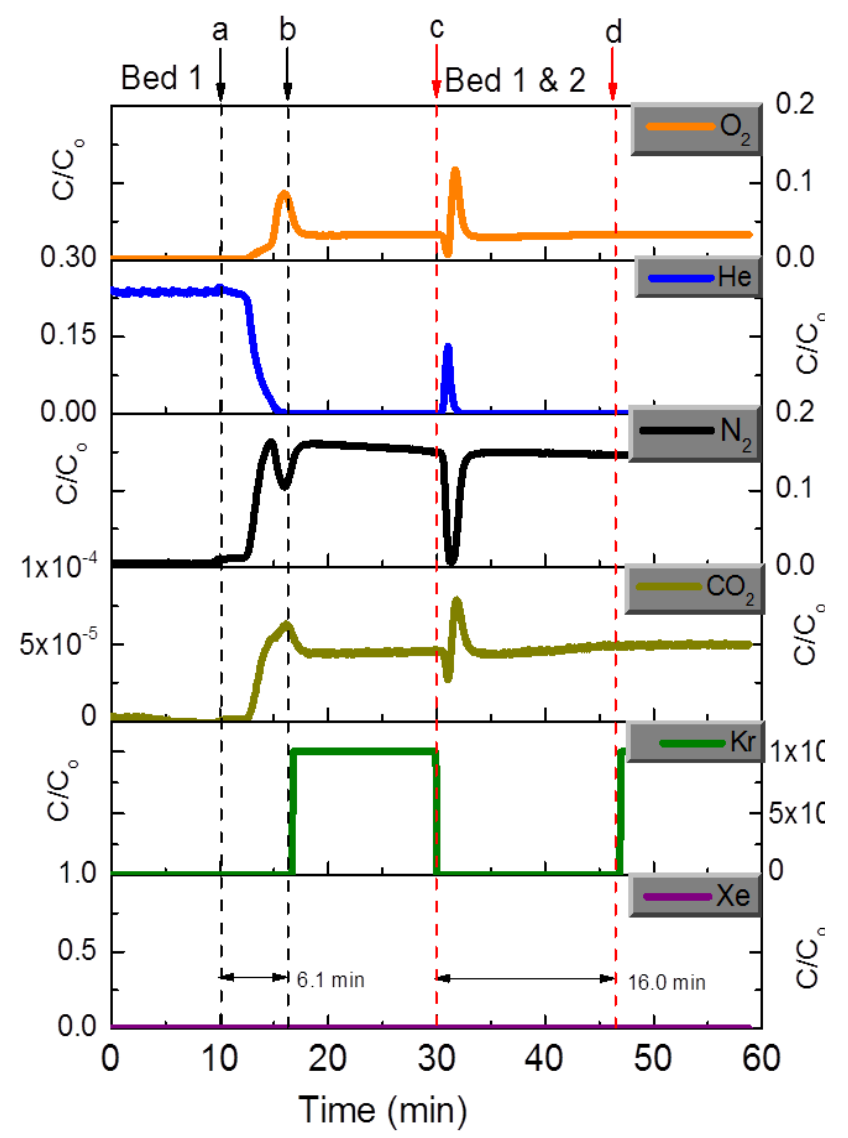

Figure 3. Breakthrough curves for gas mixtures using two bed adsorption modules at $233 \mathrm{~K}$. Adsorbents in bed 1 and 2 are NiDOBDC. a) Gas mixture [Xe (400 ppm), Kr (40 ppm) in air] into bed-1, b) gas breakthrough from bed 1, c) Gas mixture from bed 1 (Xe removed) introduced to bed 2 d) breakthrough of $\mathrm{Kr}$ from bed-1. 
passed through bed 2 containing NiDOBDC. The breakthrough time of $\mathrm{Kr}$ from the bed 2 was recorded to determine the $\mathrm{Kr}$ capacity. The results for the two experiments are shown in Figure 3 and Figure 4, respectively. In Figure 3, the breakthrough time of $\mathrm{Kr}$ from bed 1 loaded with the Ni/DOBDC was $366 \mathrm{~s}$ while the breakthrough time of $\mathrm{Kr}$ from bed 2 was $960 \mathrm{~s}$ (without $\mathrm{Xe}$ in the gas mixture). In Figure 4, the breakthrough time of $\mathrm{Kr}$ from bed 1 loaded with the NiDOBDC was $372 \mathrm{~s}$ while the breakthrough time of $\mathrm{Kr}$ from bed 2 loaded with the FMOFCu was $0.56 \mathrm{~h}$. These results clearly demonstrated that the retention time for $\mathrm{Kr}$ in bed 2 after removing Xe on bed 1 increased significantly enhancing $\mathrm{Kr}$ adsorption capacity and selectivity.

The $\mathrm{Kr}$ capacities for NiDOBDC and FMOFCu in bed 1 and 2 at $233 \mathrm{~K}$ are summarized in Table 1. Both MOF materials can adsorb ppm levels of $\mathrm{Kr}$ from the gas mixture in the absence of $\mathrm{Xe}$. The outlet gas stream leaving bed 2 contains only $\mathrm{N}_{2}, \mathrm{O}_{2}$, and $\mathrm{CO}_{2}$ demonstrating the removal of $\mathrm{Xe}$ and $\mathrm{Kr}$ in ppm level with excellent capacities and selectivities at near room temperature. The Kr capacity of NiDOBDC from a gas mixture containing $40 \mathrm{ppm} \mathrm{Kr}$ (no Xe) and $233 \mathrm{~K}$ increased from $0.24 \mathrm{mmol} / \mathrm{kg}$ to $0.61 \mathrm{mmol} / \mathrm{kg}$; an increase in capacity by a factor of 2.5 . Similarly, $\mathrm{Kr}$ capacity of the FMOFCu increased from 0.28 $\mathrm{mmol} / \mathrm{kg}$ to $1.03 \mathrm{mmol} / \mathrm{kg}$; an increase by a factor of 3.7 under the same conditions. Moreover, the results indicate if FMOFCu is used to capture $\mathrm{Kr}$ after Xe was removed, it can adsorb about 0.86 mass\% Kr. To our knowledge, this is highest $\mathrm{Kr}$ adsorption capacity at $233 \mathrm{~K}$ from gas mixture containing $40 \mathrm{ppm} \mathrm{Kr}$ in air in the absence of $\mathrm{Xe}$. The increase in $\mathrm{Kr}$ capacity is due to the reduction of competitive adsorption of Xe. The larger enhancement factor of FMOFCu is caused by the special pore size and geometry. As mentioned earlier, the FMOFCu has bottleneck windows with a diameter close to the kinetic diameter of $\operatorname{Kr}(0.360 \mathrm{~nm})$ and are smaller than the corresponding Xe diameter $(0.396 \mathrm{~nm})$. Therefore, $\mathrm{Kr}$ can diffuse into pores of the FMOFCu easier when no Xe is present to block the pathway. This can explain the significant enhancement of $\mathrm{Kr}$ capacity for the FMOFCu. As for the Ni/DOBDC, no such size restriction exists and removing $\mathrm{Xe}$ molecules in advance just provides extra adsorption sites for $\mathrm{Kr}$ molecules. Therefore, the enhancement factor for $\mathrm{Kr}$ on $\mathrm{Ni} / \mathrm{DOBDC}$ is smaller than that of the FMOFCu.

After $\mathrm{Kr}$ breakthrough from bed 2, the system was switched back to a one bed adsorption module. Adsorption bed 1 was cleaned with a He purge for $1 \mathrm{~h}$. Then, the system was switched to two-bed mode to purge bed 2 with $\mathrm{He}$. The results for the Ni/DOBDC and FMOFCu cases are shown in Figure 4. As expected, a $\mathrm{Kr}$ signal was detected and none

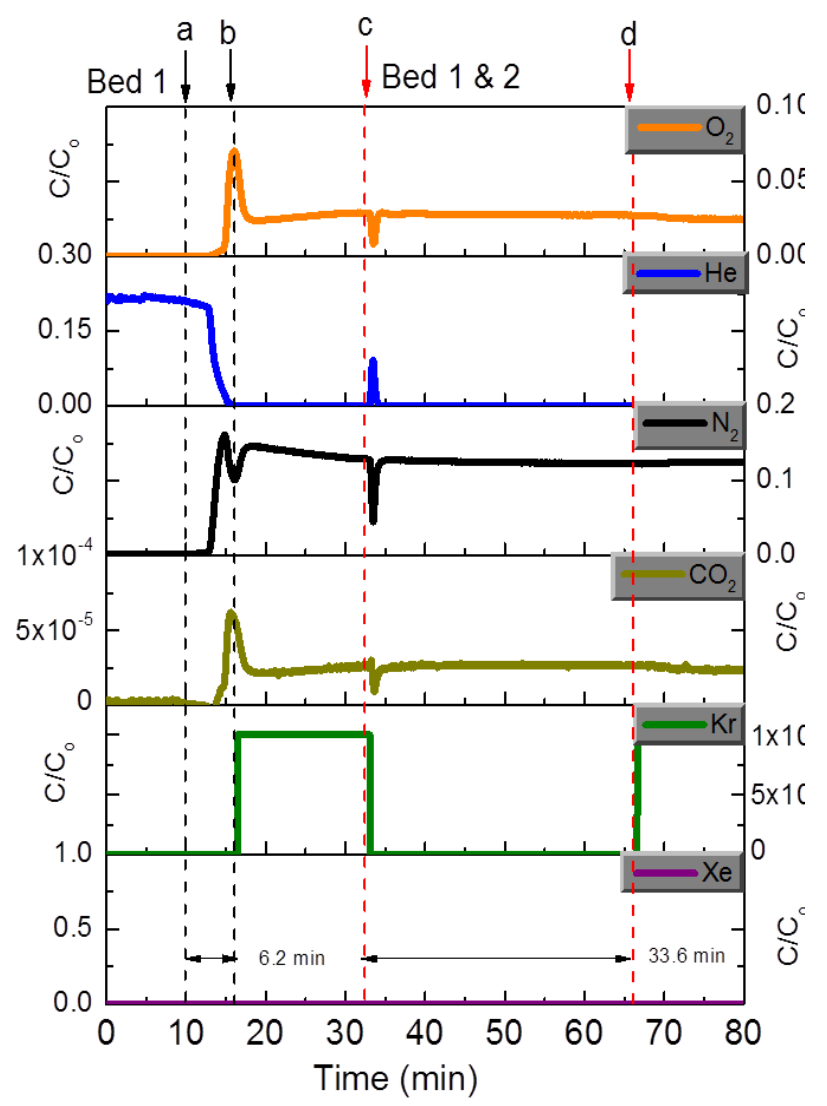

Figure 4. Breakthrough curves for gas mixture using two bed adsorption modules coupled with mass spectrometry at $233 \mathrm{~K}$. Adsorbents in bed 1 and 2 are NiDOBDC and FMOF-Cu. a) Gas mixture [Xe (400 ppm), Kr (40 ppm) in air] into bed-1, b) gas breakthrough from bed 1, c) Gas mixture from bed 1 (Xe removed) introduced to bed $2 \mathrm{~d}$ ) breakthrough of $\mathrm{Kr}$ from bed-1. 


\section{DEMONSTRATE THE REMOVAL EFFICIENCY AND CAPACITY OF MOF MATERIALS FOR KRYPTON RECOVERY}

attributable to Xe. These results verified that a two-stage adsorption process with MOFs with different characteristics as novel adsorbents can be successfully applied to immobilize ppm levels $\mathrm{Xe}$ and $\mathrm{Kr}$ separately from nuclear power plant off-gas.

Table 1. Kr capacities of two MOF materials at 233K from $40 \mathrm{ppm} \mathrm{Kr}$ in Air with and without Xe.

\begin{tabular}{|l|c|c|c|}
\hline MOF & $\begin{array}{l}\mathrm{n}_{\mathrm{Kr}}(\mathrm{mmol} / \mathrm{kg}): \\
\text { Bed 1 of } \mathbf{2}^{*}\end{array}$ & $\begin{array}{l}\mathrm{n}_{\mathrm{Kr}}(\mathrm{mmol} / \mathrm{kg}): \\
\text { Bed 2 of 2* }\end{array}$ & Enhance factor \\
\hline $\mathrm{Ni} / \mathrm{DOBDC}$ & 0.24 & 0.61 & 2.5 \\
\hline FMOF-Cu & 0.28 & 1.03 & 3.7 \\
\hline
\end{tabular}

$* 400 \mathrm{ppm} \mathrm{Xe}$ and $40 \mathrm{ppm} \mathrm{Kr}$ mixed in air was passed through bed 1 at $233 \mathrm{~K}$. The outlet gas stream with $40 \mathrm{ppm} \mathrm{Kr}$ but no Xe was passed through bed 2.
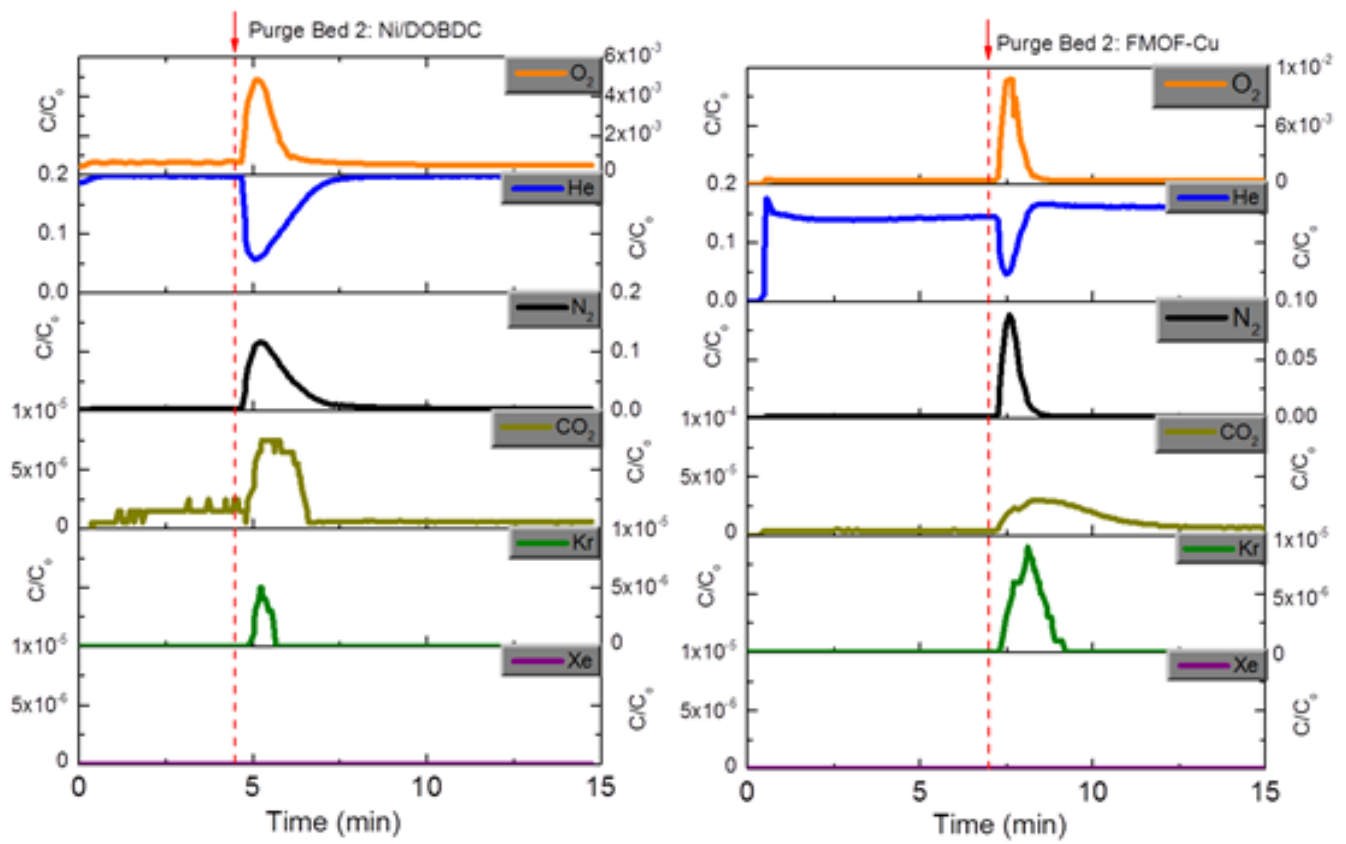

Figure 5. Desorption of Kr from bed 2 loaded with the Ni/DOBDC and FMOF-Cu by purging with He. The helium purge flow rate was $330 \mathrm{~mm}^{3} / \mathrm{s}$.

\section{Conclusions}

The removal efficiency and capacity of two MOFs (NiDOBDC and FMOFCu) for Kr recovery with two adsorption beds at near room temperature $(233 \mathrm{~K})$ has been demonstrated. Passing a mixture of $400 \mathrm{ppm}$ $\mathrm{Xe}, 40 \mathrm{ppm} \mathrm{Kr}$ in dry air through bed-1 containing NiDOBDC shows the selective capture of Xe, the outlet gas mixture from bed-1 now containing $40 \mathrm{ppm} \mathrm{Kr}$ in air is then injected through bed 2 also containing NiDOBDC where $\mathrm{Kr}$ is removed $(0.61 \mathrm{mmol} / \mathrm{kg})$. Similar experiments performed with FMOFCu instead of NiDOBDC in bed-2 result in adsorption capacities 2 to 3 times higher for $\mathrm{Kr}(1.03$ $\mathrm{mmol} / \mathrm{kg} ; 0.86$ mass\%) than from mixture containing Xe and Kr. These results show MOF materials 
continue to be promising as materials for the removal and separation of $\mathrm{Xe}$ and $\mathrm{Kr}$ from air at near room temperature and the separation of $\mathrm{Kr}$ from $\mathrm{Xe}$.

\section{ACKNOWLEDGEMENTS}

Authors would like to thank the U.S. Department of Energy (DOE), Office of Nuclear Energy for their support, in particular, Jim Bresee who has direct project oversight responsibilities. The authors would also like to thank Terry Todd (Idaho National Laboratory) and Bob Jubin (Oak Ridge National Laboratory) for their continued programmatic support and guidance.

PNNL is operated for the DOE by Battelle under Contract Number DE-AC05-76RL01830.

\section{References}

Bazan, RE, M Bastos-Neto, A Moeller, F Dreisbach, and R Staudt. 2011. "Adsorption Equilibria of $\mathrm{O}_{2}$, $\mathrm{Ar}, \mathrm{Kr}$ and Xe on Activated Carbon and Zeolites: Single Component and Mixture Data." AdsorptionJournal of the International Adsorption Society 17(2):371-83. 10.1007/s10450-011-9337-3.

Bonino, F, S Chavan, JG Vitillo, E Groppo, G Agostini, C Lamberti, PDC Dietzel, C Prestipino, and S Bordiga. 2008. "Local Structure of CPO-27-Ni Metallorganic Framework Upon Dehydration and Coordination of No." Chemistry of Materials 20(15):4957-68. 10.1021/Cm800686k.

Daney, DE. 1991. "Regenerator Performance with Noble Gas Mixtures." Cryogenics 31(10):854-61. 10.1016/0011-2275(91)90017-Q.

Eddaoudi, M, J Kim, N Rosi, D Vodak, J Wachter, M O'Keeffe, and OM Yaghi. 2002. "Systematic Design of Pore Size and Functionality in Isoreticular MOFs and Their Application in Methane Storage." Science 295(5554):469-72.

Jameson, CJ, AK Jameson, and HM Lim. 1997. "Competitive Adsorption of Xenon and Krypton in Zeolite NaA: Xe-129 Nuclear Magnetic Resonance Studies and Grand Canonical Monte Carlo Simulations." Journal of Chemical Physics 107(11):4364-72. 10.1063/1.474778.

Liu, JT, J.; Thallapally, P. K.; McGrail, B. P. 2012. "Selective Adsorption of $\mathrm{CO}_{2}$ from Flue Gases Fixed Bed Approach." J. Phys. Chem. C 116:9575-81.

Munakata, K, S Kanjo, S Yamatsuki, A Koga, and D Ianovski. 2003. "Adsorption of Noble Gases on Silver-Mordenite." Journal of Nuclear Science and Technology 40(9):695-97.

Sanchez, C, KJ Shea, and S Kitagawa. 2011. "Recent Progress in Hybrid Materials Science." Chemical Society Reviews 40(2):471-72. 10.1039/C1cs90001c.

Strachan, DM, J Chun, CH Henager, J Matyàš, BJ Riley, JV Ryan, and PK Thallapally. 2010. Summary Report for the Development of Materials for Volatile Radionuclides. Report No. PNNL-20007, Pacific Northwest National Laboratory, Richland, WA.

Strachan, DM, J Chun, J Matyàš, WC Lepry, BJ Riley, JV Ryan, and PK Thallapally. 2011. Summary Report on the Volatile Radionuclide and Immobilization Research for FY2011 at PNNL. Report No. PNNL-20807, Pacific Northwest National Laboratory, Richland, WA. 
Thallapally, PK, JW Grate, and RK Motkuri. 2012. "Facile Xenon Capture and Release at Room Temperature Using a Metal-Organic Framework: A Comparison with Activated Charcoal." Chemical Communications 48(3):347-49. 10.1039/C1cc14685h.

Thallapally, PK and DM Strachan. 2012. Initial Proof-of-Principle for near Room Temperature Xe and Kr Separation from Air with MOFs. Report No. PNNL-21452, Pacific Northwest National Laboratory, Richland, WA. 